\title{
Dogmatiek in die rigting van die Gereformeerde Ortodoksie?
}

J H Koekemoer

\section{ABSTRACT \\ Dogmatics in the direction of Reformed orthodoxy}

$J$ A Heyns plays a significant role in doing theology in the South African context. A critical analysis of his work in the field of dogmatics indicates a movement in the direction of Reformed orthodoxy. This article is a first step towards a theological discussion with him on this issue.

INLEIDENDE OPMERKINGS

Ek voldoen graag aan die versoek om by die emeritaat van 'n gewaardeerde kollega en vriend, met hom in gesprek te tree oor sy bydrae tot die teologie. Dit is inderdaad nie moontlik om met iemand wat op so 'n wye terrein in die dogmatiek bedrywig was en steeds is, en boonop so wyd en indringend gepubliseer het, in een artikel oor die hele spektrum van sy teologiese bedrywigheid in gesprek te tree nie.

Sy invloed op die kerklike terrein in Suid-Afrika en sy bydrae tot die teologie binne die Suid-Afrikaanse konteks, is eenvoudig te omvangryk om op dié wyse daaraan reg te laat geskied. Hierdie artikel wat as 'n woord van waardering gesien moet word, sal derhalwe op 'n enkele aspek van sy dogmatiek vestig en die kritiese opmerkings in hierdie verband kan bloot as voorlopig en die eerste tree tot 'n teologiese gesprek gesien word.

Die opdrag is dus tegelyk maklik en moeilik. Dit is maklik om vir iemand wat met soveel oortuiging sy pad geloop het, dankie te sê vir sy bydrae. Ons is inderdaad nog te naby aan hom om nou reeds die volle impak van sy bydrae te oorsien. Tog kan met waardering gestel word dat sy bydrae ver buite die grense van sy eie kerk gehoor is en gesprek daaroor gevoer is en steeds gevoer word. Dit is moeilik omdat hy so 'n vaardige pen het en dit nie maklik is om 'n totale greep op sy teologie te kry nie. Sy dogmatiek skep die indruk van wyd belesenheid en derhalwe het hy die gedagtes van baie groot geeste in sy denke geimplementeer.

Ek hou my egter daarvan oortuig, nadat ek opnuut weer na sy publikasies gekyk het, dat hy konsekwent 'n Calvinistiese teoloog probeer wees. Sy bydrae, so lyk dit vir my, beweeg in die rigting van die Gereformeerde ortodoksie. Om hierdie enkele stelling te staaf sal derhalwe eerstens iets oor my eie verstaan van die Gereformeerde ortodoksie aangestip moet word, terwyl pas daarna gesê kan word 
waarom ek van oortuiging is dat Heyns se dogmatick in dié rigting beweeg. 'n Persoonlike kritiese ingesteldheid teen hierdie rigting in die dogmatiek sal ook wel duidelik na vore tree. Dit sou dan ook gesien kan word as 'n vraag aan 'n gewaardeerde kollega vanuit' $n$ ander gesigspunt binne die vakbeoefening.

Volgens A E McGrath ${ }^{1}$ het die Gereformeerde ortodoksie, wat sy hoogbloei in die sewentiende eeu gehad het, sy neerslag gevind in die erkenning van die gesag van konfessionele stellings. Hierdie uitgangspunt tree duidelik in Heyns se publikasies na vore en moet positief waardeer word.

Dit is egter juis hierdie uitgangspunt wat by Otto Weber' ${ }^{2}$ 'n bepaalde kritiese ingesteldheid na vore laat tree wanneer hy daarop wys dat hierdie uitgangspunt eerder uit die dogmatiek van die reformasie as uit die reformasie self afkomstig is. Weber ${ }^{3}$ se motivering vir hierdie stelling is belangrik. Hy wys daarop dat die reformasie met sy beroep op die bronne aanvanklik nie die bedoeling gehad het om 'n dogmatiese beweging te wees nie. Die feit dat Luther nie 'n uitgewerkte Dogmatiek nagelaat het nie, word deur hom as bewys van so 'n stelling gesien. Wat wel waar is, is dat daar by die reformasie as beweging vroeg reeds die besef was dat daar nie sonder 'n mate van 'n gesistematiseerde teologie voortbeweeg kan word nie. Die Roomse Kerk met wie die gesprek gevoer is, het immers op daardie stadium oor 'n effektiewe sistematiese teologie beskik.

Die verskyning van Melanchton se Loci en Calvyn se Institusie van 1539 kan derhalwe gesien word as 'n poging om die leemte te vul, terwyl dit reeds die eerste tree in die rigting vanaf die reformasie as beweging na die reformasie as ' $n$ leerstellige saak verteenwoordig. 'n Mens sou seker ook kon sê dat die eerste tree in die rigting van die ortodoksie op dié wyse ook reeds gegee was. 'n Logies konsekwente voortbeweging op die ingeslane pad hou die moontlikheid in om by die punt te arriveer waarvan Alexander Schweizer gesê het: "Ons vadere het hulle geloof bely terwyl die meeste Christene vandag hulle belydenisskrifte glo"4. Wanneer die teologie deur so 'n proses uiteindelik sy lewendigheid verloor, word maklik vasgeval in redelik onbuigsame leerstellige uitsprake waarin die waarheid as't ware vasgevang is.

Nou wys $\mathrm{McGrath}^{5}$ tereg daarop dat in die geskiedenis van teologiese denke dit altyd so is dat ' $n$ tydperk van kreatiwiteit en beweeglikheid byna sonder uitsondering gevolg word deur 'n tydperk waarin insigte binne vaste formules en konfessies beliggaam word. Dit op sigself is natuurlik nie noodwendig ' $n$ kwade beweging nie, behalwe wanneer die formules en konfessies so versteen dat selfs die skolastiese denke wat dit ten grondslag lê as heilig beskou word. Otto Weber oordeel dat die reformatoriese teologie spoedig na die reformasie wel in so ' $n$ 
impasse beland het. Dit het duidelik ' $n$ bepaalde impasse binne die reformatoriese teologie gehad omdat dié teologie nie werklik effektief binne sulke vaste denkraamwerke ingebed kon word nie. Die rede hiervoor is dat die Ortodoksie oor die algemeen deur 'n Aristotelianisme oorheers word. Tog sou dit nie heeltemal korrek wees om die Ortodoksie as 'n suiwer Protestantse Aristotelianisme te karakteriseer nie, want dan sou, volgens Weber, die intensie van die Ortodoksie nie raakgesien word nie 6 . Hierdie intensie was naamlik om die erfenis van die reformasie te bewaar. Daarom het die uitgangspunt van die Ortodoksie die regverdigingsleer gebly en is die sola scriptura ernstig opgeneem.

Binne die Ortodoksie het iets van die lewendigheid van die Woord as gebeure egter in die slag gebly. Die noodsaak van 'n definisie om die objektiewe gesag van die Skrif te beklemtoon, het sterk na vore getree. Derhalwe het die inspirasieleer ook sterk in die gesigsveld gekom.

Van Niftrik ${ }^{7}$ is van mening dat in die proses objektiewe waarhede in hulle imposante massiwiteit ten toon gestel word om so die substansie van die kerugma te bewaar. Die objektiewe waarheid word teenoor die hoorder gestel met die eis dat hy dit moet glo. Dat hierin 'n gevaar van verstarring geleë is, hoef nie beredeneer te word nie. So 'n sisteemdenke lei inderdaad tot verstarring en 'n veruiterliking van die geloof.

Dit is juis vanweë sulke gevare dat daar in die reformasie 'n bepaalde aversie ten opsigte van die Aristoteliese skolastiek na vore getree het. Nieteenstaande die aversie het die reformasie binne 'n tydperk van vyftig jaar egter teruggeval in die skolastiek ${ }^{8}$. Soos reeds gestel, was die bestaan van 'n effektiewe en goed gesistematiseerde teologie in die Roomse kerk gedeeltelik daarvoor verantwoordelik dat die terugval wel plaasgevind het. Daar was inderdaad geen ander wetenskaplike metode behalwe dié van die Aristoteliese skolastiek waarmee die Roomse teologie teengestaan kon word nie.

In hierdie opsig is Theodore Beza veral van betekenis. Dit is veral hy wat die Aristoteliese logika in sy teologiebeoefening sterk na vore laat tree het. Nêrens in sy teologie kom dit duideliker na vore as in sy Godsleer nie ${ }^{9}$. Graafland wys verder daarop dat dit nogal merkwaardig is dat die uitverkiesingsleer in die eerste uitgawe van Calvyn se Institusie geen afsonderlike aandag ontvang nie. Dit kom wel daarin na vore, maar nie as 'n afsonderlike leerstuk nie. Wanneer Calvyn een jaar later egter sy Geneefse geloofsbelydenis die lig laat sien, gee hy aan die uitverkiesingsleer en die predestinasie wel afsonderlike aandag. In die 1539 uitgawe van sy Institusie tree die uitverkiesingsleer nog sterker na vore, maar dit is insiggewend om daarop te let dat dit ná die werk van die Heilige Gees aan die orde kom. 'n Verdere opvallende saak is dat Calvyn op die punt nie alleen die uitverkiesingsleer hanteer nie, maar ook die voorsienigheidsleer. Hierin sien Graafland 'n aanduiding dat die twee leerstukke vir Calvyn dieselfde inhoud gehad het, naamlik die 
gerigtheid op die verlossing van die mens. In die 1559 uitgawe van die Institusie vind daar ten opsigte van dié saak wel 'n verandering plaas as die voorsienigheidsleer na Boek I van die Institusie verskuif. Dit word nou geplaas waar daar oor God die Skepper gehandel word, terwyl die uitverkiesingsleer eers in Boek III aan die orde kom.

Dit lyk dus geregverdig om die afleiding te maak dat daar in Calvyn se teologie 'n sekere vloeibaarheid was en dat hy nie binne te strakke sisteme wou werk nie. Of hy altyd daarin geslaag het is 'n saak wat ook wel beredeneer kan word. By die plasing van die uitverkiesingsleer in Boek III van die Institusie versterk dit die gedagte dat dié leer 'n gelowige na-dink oor die verlossingsgebeure is en nie 'n leerstuk wat bedoel is om die mensdom in kategorieë te verdeel nie ${ }^{10}$. By Beza het die saak egter anders verloop. Hy verskuif die uitverkiesingsleer na die Godsleer toe en so word die weg gebaan na die sisteemdenke van die Ortodoksie. So verdwyn die beweeglikheid wat daar binne die dogmatiek behoort te bestaan en word dit vervang met vasstaande sisteme wat as't ware ewige raadsbesluite van God is.

Terwyl die uitverkiesingsleer vir Calvyn niks anders as 'n aspek van die leer oor die genade van God was nie, was dit vir Beza inderdaad 'n sentrale leerstuk. Dit impliseer dat die sogenoemde ewige dekrete van God, waarvan die predestinasie die belangrikste is, die uitgangspunt van teologiebeoefening word. Graafland 11 merk in hierdie verband verder op dat die feit dat Beza net soos Thomas Aquinas die uitverkiesingsleer onder die locus van die Godsleer hanteer, 'n aanduiding van hulle gemeenskaplike skolastiese metodologie is. Op dié wyse kom die Aristoteliese metafisika ook weer terug in die teologie van die reformasie.

Wanneer nou na Heyns se Dogmatiek (1978) gekyk word, val dit op dat hy sowel die uitverkiesingsleer as die voorsieningheidsleer onder die Godsleer hanteer. Dit is verder opvallend dat die uitverkiesingsleer selfs voor die Skeppingsleer geplaas word. Net maar die plasing van die verskillende loci in sy Dogmatiek lyk na 'n duiding in die rigting van die Gereformeerde Ortodoksie.

Hoewel Heyns self aandui dat hy 'n Gereformeerde dogmatiek bedryf, en hy die uitverkiesingsleer derhalwe trinitaries wil verstaan, kom daar tog bo en behalwe bogenoemde aspek van die plasing van die leerstuk, ook nog begrippe en formulerings in sy uiteensetting na vore wat moeilik anders as skolasties geïnterpreteer kan word. In hierdie verband kan onder andere na die volgende verwys word: 
Die Raad van God waarin Hy oor die ganse tydelike lewe besluit en waaruit blyk dat Hy oor alles regeer - oor wat Hy direk veroorsaak het en oor wat die mens in sy sondige opstandigheid doen - is 'n Raad waarin Hy ook oor die ewige toestand van Sy skepping besluit het ${ }^{12}$.

As die uitverkiesing 'n Goddelike daad is, kan sonder enige huiwering gesê word dat die verkiesing trinitaries verstaan moet word, en dat nie een van die Persone van die Drie-eenheid dus uitgesluit mag word nie... en dan in die intertrinitariese Raad van God het Hulle saam besluit oor die uitverkiesing... ${ }^{13} \ldots$ die uitvoering van die verkiesing is 'n geopenbaarde waarheid ${ }^{14}$.

Tog formuleer Heyns aan die ander kant self ook weer anders soos onder andere: "Nêrens in die Skrif is die boodskap aan die mens: jy is uitverkies, glo dit! Maar omgekeerd: glo in Jesus Christus en jy sal weet dat jy uitverkies is"15. Dit bly egter moeilik om baie van die formulerings, soos onder andere hierbo aangehaal, nie as spekulatiewe teologie te verstaan nie. Dat op hierdie wyse op 'n gevaarlike glybaan beland kan word, is dus nie uitgesluit nie.

Hy self sê dat "volkome swye die enigste gepaste reaksie skyn te wees"16 wanneer die mens voor God staan. Hier bevind hy hom dan volkome in lyn met die denke van onder andere Bonhoeffer ${ }^{17}$ en Ott ${ }^{18}$. Hy is weer eens in lyn hiermee as hy sê dat ons nogtans nie anders kan as om iets van die onsêbare te sê nie ${ }^{19}$. Maar juis hierdie besef van die onder woorde bring van die onsêbare behoort 'n wag voor ons mond te plaas. Juis dit behoort spekulatiewe teologie in die rigting van die ortodoksie, by die wortel af te sny.

Dit is waar dat die dieptepeilinge en beslissinge van kerk en konfessie deur die dogmatiek in 'n moderne wêreld deurdink moet word. Hierdie dogmatiese arbeid moet egter deur die Skrif gekomplementeer, gekorrigeer en gerelativeer word ${ }^{20}$. Dit gaan immers oor God en sy dade, dade waardeur die mens eksistensieël gegryp is, en juis daarom is spekulatiewe spreke gevaarlik. Die gesprek oor God en die mense gaan onverpoos voort ${ }^{21}$. In hierdie gesprek moet daarteen gewaak word dat dit nie verander in 'n bo-natuurlike aankondiging van bo-natuurlike waarhede nie. Dit moet nie gaan oor 'n soort teologiese spekulasie wat op 'n rasionele wyse geopenbaarde waarhede, met behulp van filosofiese konsepte, wil sistematiseer $n i^{22}$.

Daar sal in die dogmatiek steeds gewaak moet word teen 'n begeerte om direkte uitsprake oor God te maak. Die openbaring word immers nooit 'n soort geopenbaardheid nie. Openbaring is en bly'n daad van God. Daarom openbaar God ook nie waarhede aan ons nie, Hy openbaar Homself. In hierdie ontmoetingsrelasie wat so tot stand kom, is daar dan ook plek vir 'n teologiese nadenke oor die God wat so met die mens handel. Hierdie gesprek oor God moet egter ook altyd 
weer gesprek met God wees ${ }^{23}$. Dit is waarskynlik ook die rede waarom Bonhoeffer ${ }^{24}$ kon sê dat ons alleen in terme van ons eksistensie oor God kan praat: Wat Hy vir ons beteken, wat Hy vir ons doen en wat Hy vir ons is. Van Huyssteen ${ }^{25}$ se uitspraak dat uitsprake oor God dus eskatologies van aard is, dat dit by benadering en voorlopig is, behoort derhalwe met erns bejeën te word. Wie enigsins spekulatief oor God begin praat, met watter goeie bedoelings ookal, behoort 'n woord van Van Niftrik ${ }^{26}$ in gedagte te hou. Hy stel dat Openbaring nooit geopenbaardheid kan word nie, omdat God Hom openbaar in 'n aardse gestalte wat Hom tegelyk verberg en selfs weerspreek. Daarom is direkte en spekulatiewe uitsprake 'n gevaarlike roete om te volg. Dit gaan hier oor 'n paradoks wat verwoord moet word. In hierdie verwoording vind enige dogmatikus gou uit dat hyself ook aan die paradoks onderhewig is 27 .

Om enige belydenisuitspraak of dogma dus as ewige geopenbaarde waarhede, los van hulle ingebedheid in bepaalde historiese situasies te wil verstaan, en dit net so op die huidige geslag van toepassing te probeer maak, loop noodwendig uit op dit waaraan die Gereformeerde Ortodoksie hom skuldig gemaak het. Die taak van die dogmatikus kan nie wees om uitsprake net te herhaal nie, hy is ook geroep om die tradisie van die Christelike geloof te vertaal in die veranderde situasie van die geloof van sy eie tyd 28 .

Op hierdie wyse kan die dogmatiek altyd weer opnuut tot sinvolle uitsprake kom, maar nie tot finale uitsprake nie. In die voortgaande gesprek oor God en die mense ${ }^{29}$ bly die uitsprake van die dogmatiek altyd voorlopig. Dit is so omdat die voorwaardes waaronder die uitsprake gemaak word aanhoudend verander. Omdat die mens en sy situasie verander, verander die duiding van die Openbaring telkens, want dit kom telkens in 'n nuwe situasie ter sprake ${ }^{30}$.

Daar moet dus telkens daarteen gewaak word dat daar in die teologiebeoefening nie in 'n soort neo-ortodoksie tereg gekom word nie. In so 'n neoortodoksie sou dit ook gaan om normatiewe openbaringswaarhede, terwyl dit juis in die reformatoriese teologie om die oproep van terug na die bron gegaan het, en steeds daarom moet gaan 31 .

Die historiese relatiwiteit van kerklike leeruitsprake moet erken word in 'n poging om die Bybelse boodskap opnuut te verwoord. Om hierdie rede word die wetenskaplike metode in die dogmatiek belangrik en kry die historiese kritiek sy regmatige plek.

\section{SLOTWOORD}

Baie van die sake wat in my beredenering na vore getree het, word in Heyns se geskrifte geïnkorporeer. Dit is egter juis hierdie feit wat dit so moeilik maak om 'n greep op sy dogmatiek te kry. Terwyl hy deeglik kennis neem van alle ontwikke- 
linge op die speclveld van dic tcologie trce dalar tog spekulatiewe aspekte in sy teologie, na vore wat in die rigting van dic Ortodoksie dui. Dit is dan juis as gevolg van die spekulatiewe elemente dat daar op 'n glybaan beland kan word. Tog moet gekonstateer word dat Johan Heyns binne die Suid-Afrikaanse konteks 'n eerlike en ernstige poging aangewend het en steeds aanwend om dogmatiek te bedryf. 'n Kritiese vraag ha sy metode en die vratag of hy nie te veel in die rigting van die Ortodoksie beweeg nie, doen geen afbreuk aan die waardering vir sy werk nie. Sy bydrae maak dit juis moontlik om binne eie konteks'n sinvolle teologiese gesprek te voer.

\section{NOTAS:}

1 A E McGrath, Reformation to enlightment in P Avis, The science of Theology. Vol 1. Grand Rapids 1986, 151.

2 O Weber, Grundlagen der Dogmatik I. Neukirchen 1954, $120 \mathrm{ev.}$

3 O Weber, $a w, 120 \mathrm{ev}$.

$4 \quad$ A E McGrath, $a w, 151$.

$5 \quad$ McGrath, $a w, 151$.

6 Weber, $a w, 120 \mathrm{ev}$.

7 G C Van Niftrik, Een beroerder Israels, Nijkerk 1948, 53.

8 McGrath, $a w, 154$.

9 C Graafland, Van Calvyn tot Barth, s'Gravenhage 1987, 5.

10 W D Jonker, Uit vrye guns alleen, Pretoria 1988, $48 \mathrm{ev.}$

11 Graafland, $a w, 1987,8$.

12 J A Heyns, Dogmatick, Pretoria 1978, 77.

13 Heyns, $a w, 79$.

14 Heyns, $a w, 85$.

$15 \quad$ Heyns, $a w, 87$.

16 Heyns, $a w, 78$.

17 D Bonhoeffer, Christologie, Baarn 1982, 16.

18 H Ott, God, Richmond 1974, 99.

19 Heyns, $a w, 78$. 
20 J H Koekemoer, "Dogmatiek en Christelike Etiek binne die Fakulteit Teologie (Afd A) van die Universiteit van Pretoria", HTS 48/1 \& 2(1992), 315-328.

21 H Ott, Die Antwort des Glaubens, Stuttgard: Kreuz-Verlag 1981, 88.

22 McGrath, $a w, 155$.

23 Ott, $a w, 79$.

24 Bonhoeffer, $a w, 16$.

25 W van Huyssteen, Teologie as kritiese geloofsverantwoording, Pretoria 1987, 5.

26 Van Niftrik, $a w, 67$.

27 J H Koekemoer, Dogmatiek binne konfessionele verband, Universiteit van Pretoria 1989, 6.

28 T B Ommen, The hermeneutic of dogma, Montana 1975, 153.

29 Ott, $a w, 1981,88$.

30 Koekemoer, HTS 48/1 \& 2 (1992), 327.

31 K Cauthen, Systematic Theology. A modern Protestant Approach, New York: Edwin Mellen Press 1986. 